NEWS

\title{
Academy affirms hockey-stick graph
}

\section{WASHINGTON DC}

It's probably the most politicized graph in science - an icon of the case for climate change to some, and of flawed science in the service of that case to others - and it has coloured the climate-change debate for nearly a decade. Now the US National Academy of Sciences (NAS) has weighed in with a report on the 'hockey-stick' plot, which it hopes will finally lay the controversy to rest.

The graph purports to chart global temperatures over the past millennium; a sharp rise at the current end is the 'blade' that makes the otherwise flattish line look like a hockey stick. Climate groups have claimed it as evidence of dangerous global warming; sceptics, especially in the United States and Canada, have questioned the study's merit and statistical methodology.

In its report, released on 22 June, the NAS committee more-or-less endorses the work behind the graph. But it criticizes the way that the plot was used to publicize dimatechange concerns. And it leaves open big questions about whether researchers should be obliged to make their data available (see 'Plotting a course').

"We roughly agree with the substance of their findings," says Gerald North, the committee's chair and a climate scientist at Texas A\&MUniversity in College Station. In particular, he says, the committee has a "high level of confidence" that the second half of the twentieth century was warmer than any other period in the past four centuries. But, he adds, claims for the earlier period covered by the study, from $\mathrm{AD} 900$ to 1600 , are less certain. This earlier period is particularly important because global-
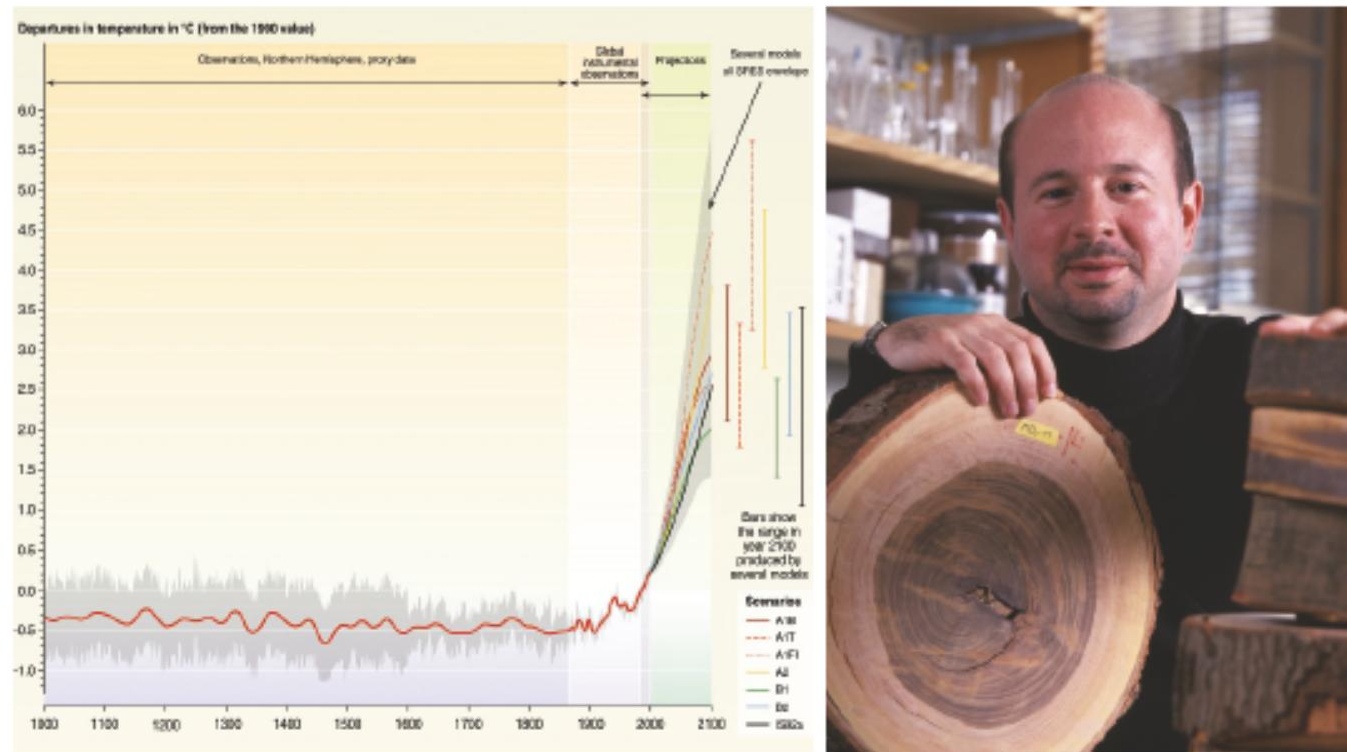

Cause for controversy: Michael Mann used proxies for climate change, such as tree rings, to produce a picture of Earth's changing climate over the past millennium.

warming sceptics daim that the current warming trend is a rebound from a little ice age' around 1600 . Overall, the committee thought the temperature reconstructions from that era had only a two-to-one chance of being right.

The graph arose from the work of Michael Mann, a dimatologist now at Pennsylvania State University in University Park, and two colleagues. In two papers published in 1998 and 1999, Mann's team examined tree rings, ice cores and other 'proxies' of past climate, and used them to reconstruct the Northern Hemisphere's temperature over the past millennium (M. E. Mann et al. Nature 392, 779-787; 1998 and M. E. Mann et al. Geophys. Res. Lett. 26, 759-762; 1999).

The analysis was complex because the proxies were geographically dispersed and contained uncertainties that are often difficult to gauge. For example, the growth of bristle-cone pine trees, which played an important role in the Mann study, depends on temperature, but also rainfall. The researchers concluded in their 1999 paper that "the 1990 s are likely the warmest decade, and 1998 the warmest year, in at least a millennium", and included a graph showing a sharp upturn in temperature from about 1900 onwards. The plot soon became

\section{PLOTTING A COURSE}

The US National Academy of Sciences (NAS) report may help put the 'hockey-stick' debate to rest, but it leaves open a larger question about who should have access to researchers' data.

Mann's critics complained thathe would not share the methodological details or raw data that would enable them to assess his work. In June 2005, congressman Joe Barton (Republican, Texas) wrote to the hockey-stick study's authors demanding that, among other things, they list their funding agencies and provide access to their raw data and algorithms. Letters were also sent to the NationalScience Foundation and the Intergovernmental Panel on Climate Change demanding information on the work (see Nature 436,7; 2005). Many in the scientific community were shocked by the letters' aggressive tone, but Mann did supply information about how to access the data he used.
Barton and his committee have commissioned their own statistical analysis, which is ongoing.

The NAS panel largely demurred on questions of data sharing, saying that although opennessis generally good, suchissues are "discipline dependent". "We thought that question was a little big for what we were trying to do here," says committee chair Gerald North.

That doesn'tmean the matter is closed. Bill Kearney, the academy's director of media relations, says that the NAS is putting together a panel to examine issues of data sharing in all fields. The panel, which will convene later this summer, "will be a broad look at access across the board", says Kearney.

For now, politicians will probably intervene as they seefit, says David Goldston, chief of staff for the House Committee on Science: "As the scientific community continues to wrestle with this, it will continue to be an issue."

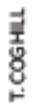


known as the hockey stick, and was featured prominently in the executive summary for policy-makers in the 2001 report on global warming from the Intergovernmental Panel on Climate Change (IPCC).

Shortly after it appeared in the report, two Canadians, economist Ross McKitrick and mineral-exploration consultant Stephen McIntyre, attacked the methodology behind the graph, claiming that it was based on insufficient data and flawed statistical analysis. US politicians amplified their complaints, most prominently Representative Joe Barton (Republican, Texas), who in 2005 wrote to Mann demanding he share his data with critics and congressional overseers. In an effort to quell the controversy, the chairman of the House Committee on Science, Representative Sherwood Boehlert (Republican, New York), commissioned the academy to examine the earlier work.

The academy essentially upholds Mann's findings, although the panel concluded that systematic uncertainties in climate records from before 1600 were not communicated as clearly as they could have been. The NAS also confirmed some problems with the statistics. But the mistakes had a relatively minor impact on the overall finding, says Peter Bloomfield, a statistician at North Carolina State University in Raleigh, who was involved in the latest report. "This study was the first of its kind, and they had to make choices at various stages about how the data were processed, he says, adding that he "would not be embarrassed" to have been involved in the work.

Panel members were less sanguine, however, about whether the original work should have loomed so large in the executive summary of the IPCC's 2001 report. ${ }^{\text {* The }}$ IPCC used it as a visual prominently in the report," says Kurt Cuffey, a panel member and geographer at the University of California, Berkeley. "I think that sent a very misleading message about how resolved this part of the scientific research was."

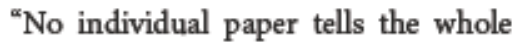
story, agrees North. "It's very dangerous to pull one fresh paper out from the literature"

Mann says that he is "very happy" with the committee's findings, and agrees with the core assertion that more must be done to reduce uncertainties in earlier periods. ${ }^{\alpha} \mathrm{We}$ have very little long-term information on the Southern Hemisphere and large parts of the ocean," he says. As for the report's effect on the policy debate, Mann says: "Hopefully this is the beginning of us, as a community, putting that silliness behind us."

Geoff Brumfiel

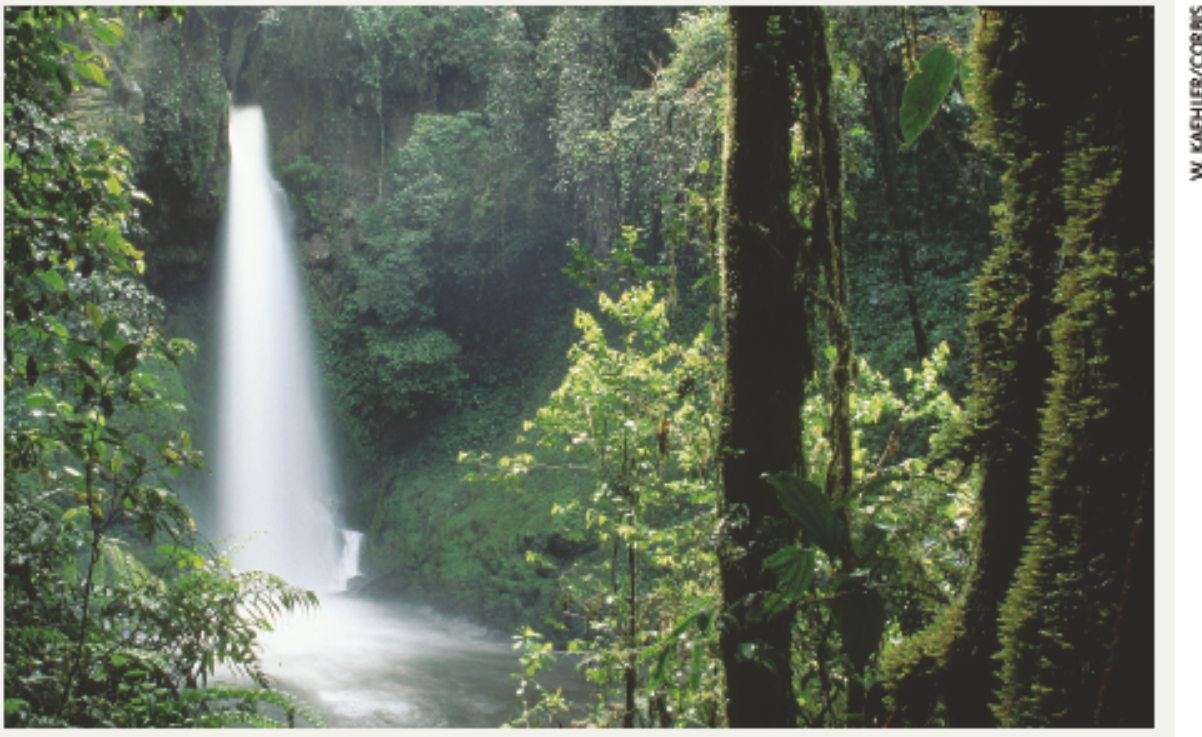

\section{Experts comb tropics for clues to vCJD}

\section{Some people in Papua New Guinea whoonce feasted on their own relatives didnot succumb to the prion disease kuruuntil 50 years later, say researchers who have laboriously tracked down the last sufferers in remote villages. The discovery renews concern that another human prion disease, variant Creutzfeldt- Jakobdisease (VCJD), might be incubating silently in some} populations and could rear its headdecades fromnow.

Neurologists have long been fascinated by kuru, which caused an unprecedented epidemic of neurodegenerative disease in the Fore people of Papua New Guinea that peaked in the 1950 s and early 1960 s. In deathrituals, familiessteamed and ate the bodies of their relatives - along with, it was later discovered, infectious prion proteins that caused the debilitating andfatal disease. The ritual was prohibited in the mid-1950s by the Australian authorities whogoverned that part of Papua New Guinea, and the disease eventually became less frequent.

Interestinkurureawakened with the realization that $\mathrm{VCJD}$, transmitted from cows infected with bovine spongiform encephalopathy, mightcause a similarepidemicamong those who ate infected meat in the 1980 s and 1990 s. So far, only 156deaths from vCJD have been reported in Britain, the worst-affected country, and the number of newcases peaked in 2000 , suggesting that $v C J D$ takes about ten years to incubate. But debate continues about whether anotherwave of cases could yet appear.

John Collinge at University College London andhis colleagues went to Papua New Guinea to findout. Mostpeople with kuru have already died, but the teamrampedupexisting disease monitoring to find the last of the epidemic. Working withlocal communities, they scoured isolated villages that are typically more than 2,000 metres above sea level, lost in dense rainforest and connected only by tracks. "It'sarduous trekking," says Collinge.

Between 1996 and 2004, the researchers found what they believe are the last 11 cases of kuru. Patients' histories were collected, to piece together when they were probably infected. The longest incubation time was calculated to be at least 56 years, and perhaps seven yearslonger although the average incubation time seems to be 12 years (J. Collinge et aL Lancet 367,2068-2074;2006). "For the first time we can see the extraordinary incubation periodinhuman prion disease," says Collinge. "It's sobering that, half a century on, this disease has not disappeared."

Collinge says that vCJD could have a much longer average incubation time, of 30 years or more, because the prions are passing from cows tohumans rather than between humans. Aspecies barrier extends incubation times in animal tests. People who have already succumbed to VCD might have been particularly genetically susceptible, as other evidence has suggested.

Mathematical modelsused to predict the size of a VCJD epidemic could now include these findings. "Most people seem to think we're over the worst," Collinge says. "We have to be cautious about assuming this disease is going away." Helen Pearson 